\title{
Desulphurization of Molten Iron Stirred by Rocking Motion*
}

\author{
By Sumio SHIOMI,** Nobuo SANO, ${ }^{* *}$ and Yukio MATSUSHITA**
}

\section{Synopsis}

By the use of laboratory scale rocking furnace, carbon saturated liquid iron $([\% \mathrm{~S}]=0.5 \sim 0.7)$ was desulphurized by calcium carbide powder in the temperature range from $1250^{\circ}$ to $1450^{\circ} \mathrm{C}$ with the rocking speed of 0 to $36 \mathrm{c} / \mathrm{min}$, and the mechanism of this reaction was discussed based on the results obtained.

The mass transfer coefficient $K$ obtained from the experimental results may be expressed by the following equation.

$$
K=\left(1.6 \times 10^{10} \cdot R_{c}+1.1 \times 10^{10}\right)^{1 / 2} \exp (-40000 / R T)
$$

where $R_{c}$ is the rocking speed, $R$ and $T$ are the gas constant and temperature $\left({ }^{\circ} \mathrm{K}\right)$, respectively.

From the value of apparent activation energy obtained, however, it could not be definitely determined whether the desulphurization process is controlled by the chemical reaction or the diffusion.

\section{Introduction}

As far as the extent of desulphurization during the steelmaking process of iron is limited, it is desirable to remove sulphur as much as possible in advance of this process.

Recently, many effective methods of desulphurization have been practically used, in which solid desulphurizers were used and the mixing condition of the iron bath and the desulphurizer was improved.

For instance, the methods of Domnarfvet, ${ }^{1)}$ shaking ladle ${ }^{2)-4}$ and others affect favorably the desulphurization in a short time.

The present authors have been studying the kinetics of the desulphurization of iron with lime and calcium carbide powder by using a small scale rocking furnace. Since magnesia was used for the lining of the wall of the furnace at the early stage of this work, the same experimental conditions were hardly maintained for all the experiments. This problem was solved by replacing magnesia lining by a graphite cylinder and the reproducible results were obtained for every experiment on the desulphurization with calcium carbide powder. Thus, the mechanism of desulphurization under the conditions mentioned above was discussed from the results obtained.

\section{Experimental Procedure}

The graphite cylinder shown in Fig. 2 was set inside of the rocking furnace, as shown in Fig. 1. Four kilograms of carbon saturated iron containing 0.5 to $0.7 \%$ of sulphur which was previously prepared was melted and held at temperatures of $1250^{\circ}, 1350^{\circ}$, and $1450^{\circ} \mathrm{C}$. After taking out the sample metal of 7 to $8 \mathrm{~g}$ from the melt by drawing with a quartz tube of $9 \mathrm{~mm}$ ID, the quartz tube was sealed at the end and bored a hole of $5 \mathrm{~mm}$ ID above the sealed end. Then, $240 \mathrm{~g}$ of $\mathrm{CaC}_{2}$ powder ( $150 \mathrm{~g}$ of the powder is 14 to 30 mesh, and the rest is 30 to 48 mesh) were spread over the metal surface in a short time and the rocking motion was started. Samples were taken out of the melt at various times by using the method above mentioned and were subjected to the conventional chemical analysis of sulphur. Temperatures were measured by two thermocouples of $\mathrm{Pt}-\mathrm{Pt} \cdot \mathrm{Rh} 13 \%$, one of which was set at the exterior of the graphite cylinder and the other was immersed in the bath intermittently.

\section{Experimental Results and Discussion}

The motion of the furnace during the rocking and the condition of contact between the lining and $\mathrm{CaC}_{2}$ powder are schematically shown in Fig. 3. The graphite wall had a tilt of 60 degrees on both sides, but

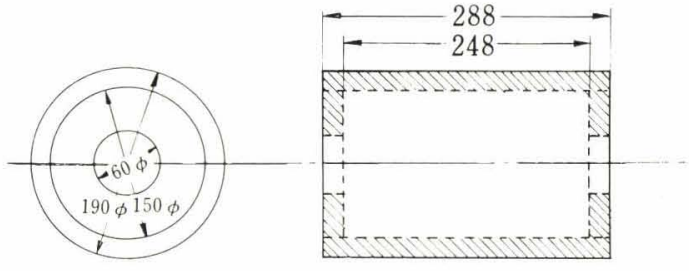

Fig. 2. Schematic representation of graphite cylinder (unit: $\mathrm{mm}$ )
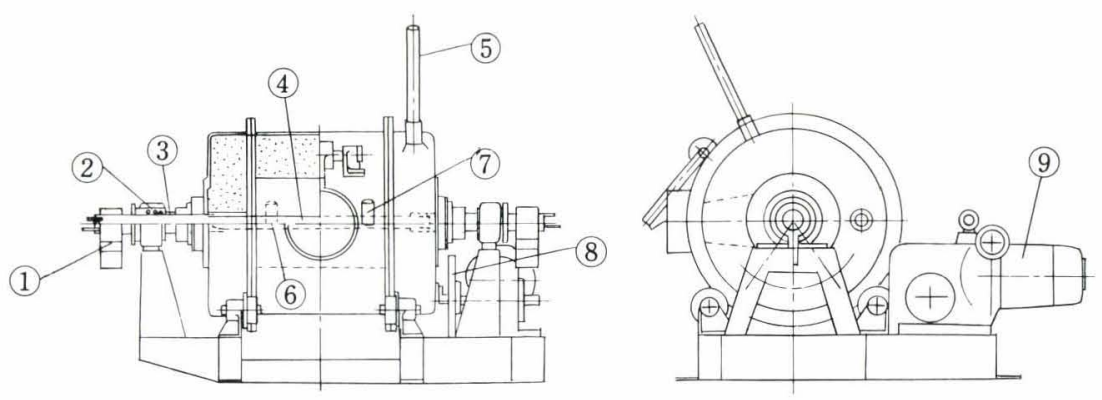

(1) Electrode terminal

(2) Spring (for pressing electrode)

(3) Electrode (water cooled)

(4) Graphite resistance heating element

(5) Handle (for inclining the body)

(6) Gas outlet

(7) Gas inlet

(8) Driving gears for rocking motion

(9) Motor (for rocking motion)

Fig. 1.

$10 \mathrm{~kg}$ rocking furnace using graphite resistance heating element

* Originally published in Tetsu-to-Hagané, 56 (1970), 14, in Japanese. English version received August 26, 1970.

** Department of Metallurgy and Materials Science, University of Tokyo, Tokyo 113. 


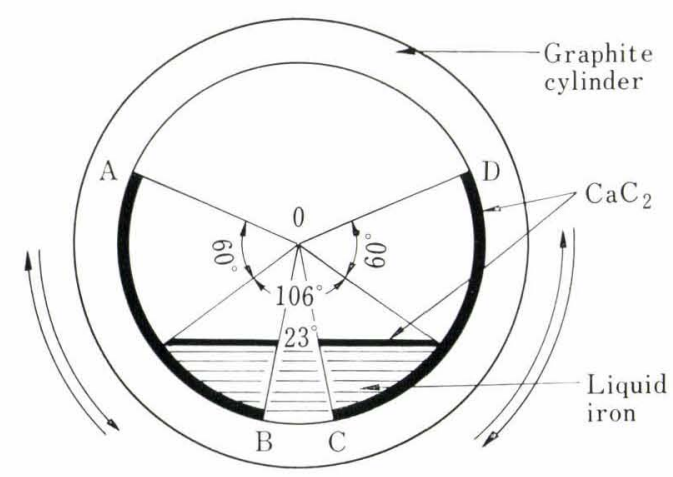

Fig. 3. Model of the motion of liquid iron inside the rocking furnace

the movement of the melt was observed to be much smaller than 60 degrees at any rocking cycle. Most of $\mathrm{CaC}_{2}$ powder stuck on the wall within a short time and the remainder floated on the bath in the globular shape of various sizes owing to the binding with liquid iron. The powder stuck more easily on the wall as the rocking speed decreased and the temperature increased. The contact area between the wall and the melt, and the surface area of the bath at static state were about $270 \mathrm{~cm}^{2}$ and $300 \mathrm{~cm}^{2}$, respectively.

Figure 4 shows the relationships between $[\% \mathrm{~S}]$ and time for unrocked melts at $1250^{\circ}, 1350^{\circ}$ and $1450^{\circ} \mathrm{C}$. On the other hand, Fig. 5 shows the results obtained at a rocking cycle of 13 cycles per minute for various temperatures. The results for various rocking cycles at $1350^{\circ} \mathrm{C}$ are shown in Fig. 6. From these figures, it is obvious that the rate of desulphurization increases as the temperature and the rocking cycle increase.

By the addition of rocking motion, more than $90 \%$ of sulphur was removed within 15 minutes except the case at $1250^{\circ} \mathrm{C}$ and 13 cycles per minute.

The mechanism of desulphurization for the period of initial $15 \mathrm{~min}$ after the begining of experiments will be discussed below. If the reaction of desulphurization can be expressed by Eq. (1),

$$
\underline{\mathrm{S}}+\mathrm{CaC}_{2}=\mathrm{CaS}+2 \mathrm{C}
$$

the rate determining step of this reaction is considered to be one of the following three:

(1) Diffusion of sulphur in the boundary layer of the metal.

(2) Chemical reaction at the interface between $\mathrm{CaC}_{2}$ and the melt.

(3) Diffusion of sulphur in CaS to interface between $\mathrm{CaC}_{2}$ and $\mathrm{CaS}$.

Unfortunately, there is no available diffusivity data for item (3), except the diffusivity of sulphur in NiS $\left(3.1 \times 10^{-7} \mathrm{~cm}^{2} / \mathrm{sec}^{5)}\right.$ at $1250^{\circ} \mathrm{C}, 1.7 \times 10^{-6} \mathrm{~cm}^{2} / \mathrm{sec}^{5)}$ at $1350^{\circ} \mathrm{C}, 8.7 \times 10^{-6} \mathrm{~cm}^{2} / \mathrm{sec}^{5)}$ at $1450^{\circ} \mathrm{C}$ ). The diffusivity of sulphur in liquid iron saturated with carbon were measured to be $2.3 \times 10^{-5}{ }^{6)} \sim 7.1 \times 10^{-6} \mathrm{~cm}^{2} / \mathrm{sec}^{7)}$ at $\quad 1250^{\circ} \mathrm{C}, \quad 2.7 \times 10^{-5}{ }^{6)} \sim 1.1 \times 10^{-5} \mathrm{~cm}^{2} / \mathrm{sec}^{7)}$ at $1350^{\circ} \mathrm{C}, 3.2 \times 10^{-5}{ }^{6)} \sim 1.6 \times 10^{-5} \mathrm{~cm}^{2} / \mathrm{sec}^{7)}$ at $1450^{\circ} \mathrm{C}$. Thus, it is considered that the diffusion of sulphur in CaS may be slower than in liquid iron.

It is therefore reasonable to assume that $\mathrm{CaC}_{2}$ does

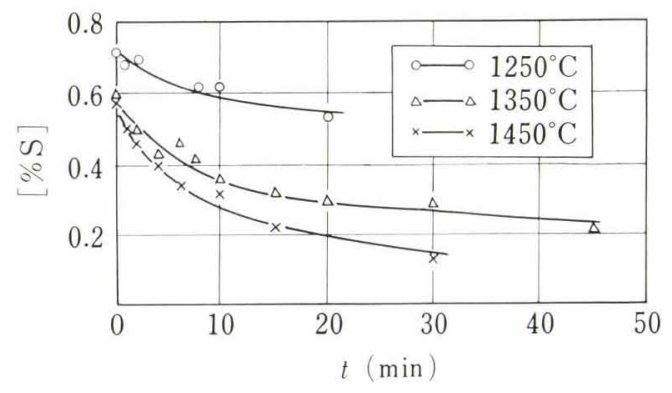

Fig. 4. Relation between $[\% \mathrm{~S}]$ and time at $1250^{\circ}, 1350^{\circ}$, and $1450^{\circ} \mathrm{C}(0 \mathrm{c} / \mathrm{min})$

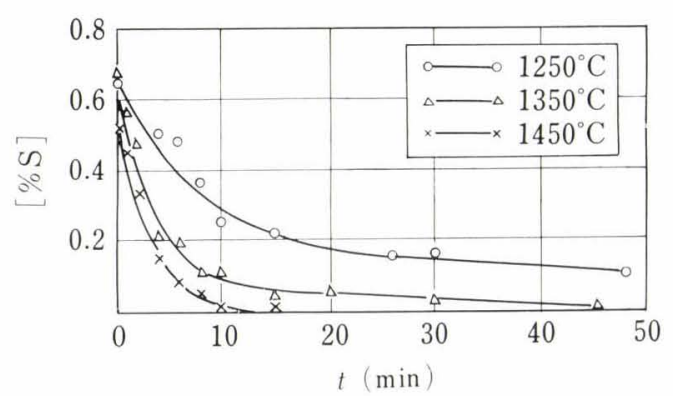

Fig. 5. Relation between $[\% \mathrm{~S}]$ and time at $1250^{\circ}, 1350^{\circ}$, and $1450^{\circ} \mathrm{C}(13 \mathrm{c} / \mathrm{min})$

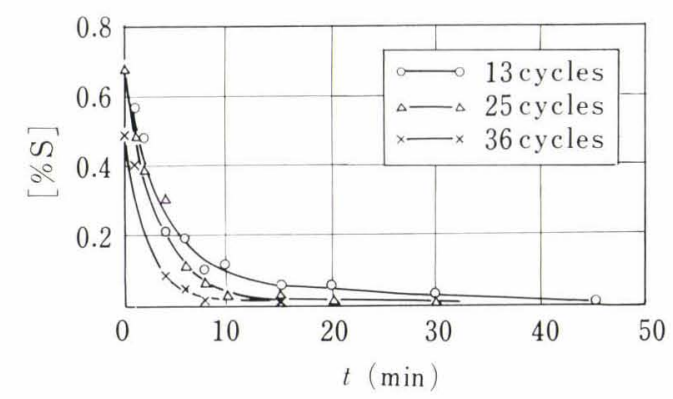

Fig. 6. Relation between $[\% \mathrm{~S}]$ and time at $1350 \% \mathrm{C}(13,25$, and $36 \mathrm{c} / \mathrm{min}$ )

not act as the desulphurizer any more once $\mathrm{CaC}_{2}$ is covered with the reaction product having the form of CaS. The rate determing step may be (1) or (2) as far as a fresh surface of $\mathrm{CaC}_{2}$ is present.

When the reaction is controlled by the step (1), the flux of sulphur, which diffuses from the bath to the interface, is shown by Eq. (2).

$$
\begin{aligned}
\dot{n} & =-\left(D_{\mathrm{S}} A / \delta\right)\left(C_{\mathrm{S}}-C_{\mathrm{S}}^{\circ}\right) \\
& =-\left(D_{\mathrm{S}} A / \delta\right)\left([\% \mathrm{~S}]-[\% \mathrm{~S}]^{\circ}\right) \cdot \rho / 100 \cdot M_{\mathrm{S}}
\end{aligned}
$$

where,

$\dot{n}$ : the quantity of sulphur removed $\left(\mathrm{mol} / \mathrm{sec} \cdot \mathrm{cm}^{2}\right)$

$D_{\mathrm{S}}$ : the diffusivity of sulphur in the metal $\left(\mathrm{cm}^{2} / \mathrm{sec}\right)$

$A:$ the interfacial area $\left(\mathrm{cm}^{2}\right)$

$\delta$ : the boundary layer thickness in the metal $(\mathrm{cm})$

$C_{\mathrm{S}},[\% \mathrm{~S}]$ : the concentration of sulphur in liquid iron $\left(\mathrm{mol} / \mathrm{cm}^{3}\right.$, $\mathrm{w} / \mathrm{o})$

$\mathrm{C}_{\mathrm{S}}^{\circ}[\% \mathrm{~S}]^{\circ}$ : the concentration of sulphur at the interface $\left(\mathrm{mol} / \mathrm{cm}^{3}, \mathrm{w} / \mathrm{o}\right)$

$\rho:$ the density of liquid iron $\left(\mathrm{g} / \mathrm{cm}^{3}\right)$

$M_{\mathrm{S}}$ : the molecular weight of sulphur.

The quantity of sulphur converted to CaS by the chemical reaction at the interface is given by the following equation. 
$\dot{n}=-k A\left(C_{\mathrm{S}}^{\circ}-C_{\mathrm{S}}^{*}\right)=-k A\left([\% \mathrm{~S}]^{\circ}-[\% \mathrm{~S}]^{*}\right) \cdot \rho / 100 \cdot M_{\mathrm{S}}$

where,

$k$ : the coefficient of reaction rate

$C_{\mathrm{S}}{ }^{*},[\% \mathrm{~S}]^{*}$ : the equilibrium concentration of sulphur in the metal $\left(\mathrm{mol} / \mathrm{cm}^{3}, \mathrm{w} / \mathrm{o}\right)$

The value of $[\% \mathrm{~S}]^{*}$ is very small, that is, the values thermodynamically calculated are $1.63 \times 10^{-8}$ at $1200^{\circ} \mathrm{C}, \quad 6.65 \times 10^{-7}$ at $1415^{\circ} \mathrm{C}$. Assuming that $[\% \mathrm{~S}]^{*}$ is zero, Eq. (4) is obtained by the combination of Eqs. (2) and (3).

$$
\dot{n}=-\left(D_{\mathrm{S}} k A / \delta k+D_{\mathrm{S}}\right) \cdot[\% \mathrm{~S}] \rho / 100 \cdot M_{\mathrm{S}}
$$

Since $\delta K \gg D_{\mathrm{S}}$ in the case that the diffusion of sulphur is the rate determining step, Eq. (4) becomes,

$$
\dot{n}=-\left(D_{\mathrm{S}} A / \delta\right) \cdot[\% \mathrm{~S}] \rho / 100 \cdot M_{\mathrm{S}}
$$

On the other hand, if the chemical reaction at the interface is the rate determining step, Eq. (6) is given because of $\delta k \ll D_{\mathrm{S}}$

$$
\dot{n}=-k A \cdot[\% \mathrm{~S}] \rho / 100 \cdot M_{\mathrm{S}}
$$

Equations (5) and (6) can be rewritten as follows by the use of weight percent.

$$
\begin{aligned}
& d[\% \mathrm{~S}] / d t=-\left(D_{\mathrm{S}} A / \delta\right) V \cdot[\% \mathrm{~S}] . \\
& d[\% \mathrm{~S}] / d t=-(k A / V) \cdot[\% \mathrm{~S}] \ldots .
\end{aligned}
$$

where, $V:$ the volume of liquid iron $\left(\mathrm{cm}^{3}\right)$.

Integrating Eqs. (7) and (8), one obtains,

$$
\begin{aligned}
& \log [\% \mathrm{~S}]=-\left(D_{\mathrm{S}} A / 2.3 \delta V\right) \cdot t+\log [\% \mathrm{~S}]^{i} \\
& \log [\% \mathrm{~S}]=-(k A / 2.3 V) \cdot t+\log [\% \mathrm{~S}]^{i} .
\end{aligned}
$$

where, $[\% \mathrm{~S}]^{i}$ : the initial concentration of sulphur in the metal $(\mathrm{w} / \mathrm{o})$.

In both cases, the relationship between $\log [\% \mathrm{~S}]$ and time should be linear. As shown in Figs. 7, 8, and 9, linear relations holds between $\log [\% \mathrm{~S}]$ and time for the experimental results obtained under conditions mentioned above.

It is confirmed from this fact that either diffusion of sulphur or the chemical reaction is the rate determing step. In order to clarify the rate determining step, the following consideration has been made for the activation energies of diffusion and of chemical reaction.

The relationship between $\delta$ and Reynolds number of Re can be given by Eq. $(11)^{8)}$ under the present conditions.

$$
\delta=\gamma / \sqrt{ } \operatorname{Re}, R e=r u \rho / \eta
$$

where, $\gamma:$ the constant

$r:$ the characteristic length

$u$ : the velocity of fluid

$o$ : the density of fluid

$\eta$ : the viscosity coefficient of fluid.

At a constant temperature, Eq. (11) can be simplified as follows.

$$
\delta=K_{1} / \sqrt{u} \quad\left(K_{1}=r / \sqrt{r \rho / \eta}\right)
$$

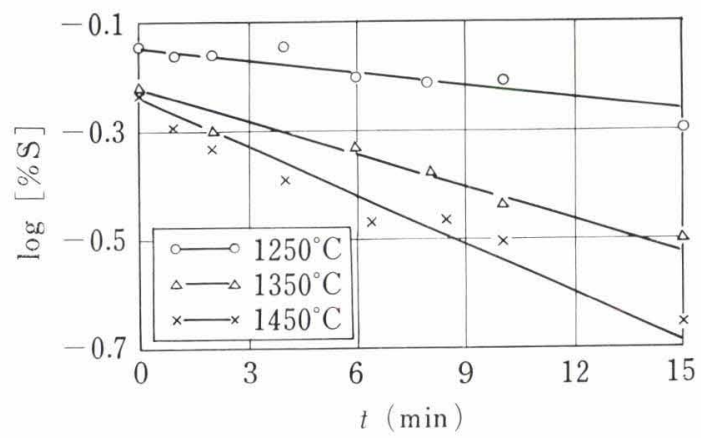

Fig. 7. Relation between $\log [\% \mathrm{~S}]$ and time at $1250^{\circ}$ and $1350^{\circ} \mathrm{C}(0 \mathrm{c} / \mathrm{min})$

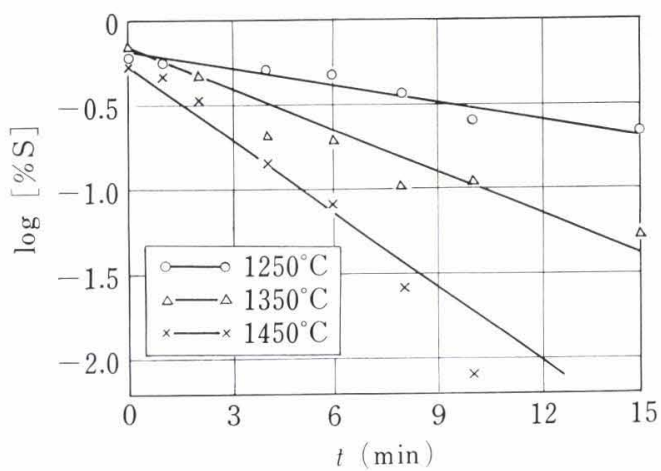

Fig. 8. Relation between $\log [\% \mathrm{~S}]$ and time at $1250^{\circ}, 1350^{\circ}$, and $1450^{\circ} \mathrm{C}(13 \mathrm{c} / \mathrm{min})$

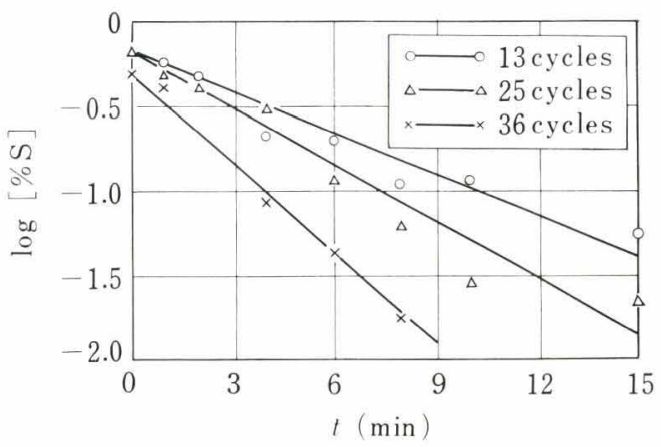

Fig. 9. Relation between $\log [\% \mathrm{~S}]$ and time at $1350^{\circ} \mathrm{C}(13$, 25 , and $36 \mathrm{c} / \mathrm{min}$ )

If $u$ is linear with cycles $R_{c}$, that is, $u=a R_{c}+b$, it becomes,

$$
\delta=K_{1} / \sqrt{a R_{c}+b}
$$

According to the experimental results, the temperature and rocking cycles do not affect the area of chemical reaction. Combining Eqs. (9) and (13), one obtaines,

$$
\left(D_{\mathrm{S}} A / \delta\right)^{2}=\left(D_{\mathrm{S}} A / K_{1}\right)^{2}\left(a R_{c}+b\right)
$$

Therefore, if the diffusion is the rate determining step, the relationship between square of $\left(D_{\mathrm{S}} A / \delta\right)$ and $R_{c}$ should be linear. Figure 10 shows that this relationship is realized for all the case including $R_{c}=0$.

The relationship between $\delta$ and temperature will be given for the constant $R_{c}$. As the effect of temperature on the density of liquid iron is small, the relationship between density and viscosity coefficient of liquid iron may be given by Eq. (15). 


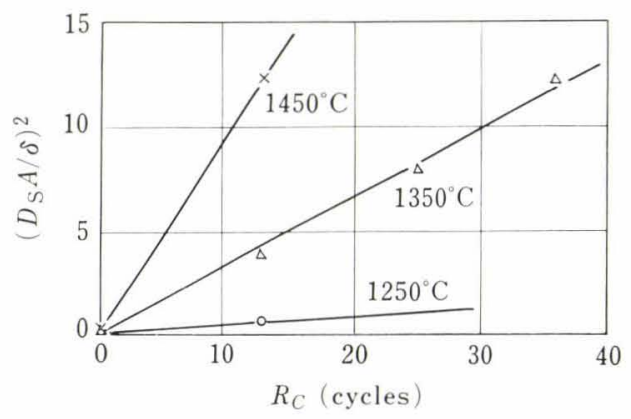

Fig. 10. Relation between $\left(D_{\mathrm{S}} A / \delta\right)^{2}$ and $R_{c}$

$$
\delta=K_{2}(\eta)^{1 / 2} \quad\left(K_{2}=\gamma /(r u \rho)^{1 / 2}\right) .
$$

From Eqs. (13) and (15), Eq. (16) is obtained.

$$
\delta=K_{3}\left\{\eta /\left(a R_{c}+b\right)\right\}^{1 / 2} \quad\left(K_{3}=\gamma /(r \rho)^{1 / 2}\right)
$$

Based on Eq. (16), the relationship between $\delta$ and $T$ can be expressed as follows.

$$
\begin{aligned}
\delta & =K_{3} \eta_{0}^{1 / 2} \exp \left(E_{\eta} / 2 R T\right) /\left(a R_{c}+b\right)^{1 / 2} \\
(\eta & =\eta_{0} \exp \left(E_{\eta} / R T\right), \ldots \ldots \ldots \ldots \ldots \ldots \ldots \ldots \ldots \ldots \ldots \ldots \ldots
\end{aligned}
$$

where, $E_{\eta}$ : the activation energy of viscosity

$$
R \text { : gas constant. }
$$

Thus, it becomes,

$$
\begin{gathered}
D_{\mathrm{S}} A / \delta=A D_{o} \exp \left(-E_{D} / R T\right) \\
\left(a R_{c}+b\right)^{1 / 2} / K_{4} \exp \left(E_{\eta}^{\prime} / R T\right) \\
\left(K_{4}=K_{3} \eta_{0}^{1 / 2}, E_{\eta}^{\prime}=E_{\eta} / 2\right) \\
D_{\mathrm{S}}=D_{o} \exp \left(-E_{D} / R T\right) \ldots
\end{gathered}
$$

where, $E_{D}$ : the activation energy of diffusion.

Squaring the both side of Eq. (18), it gives

$$
\begin{gathered}
\left(D_{\mathrm{S}} A / \delta\right)^{2}=\left(\alpha R_{c}+\beta\right) \exp \left\{-2\left(E_{D}+E_{\eta}^{\prime}\right) / R T\right\} \\
\alpha=a\left(D_{0} A / K_{4}\right)^{2}, \beta=b\left(D_{O} A / K_{4}\right)^{2} \ldots \ldots \ldots \ldots . . .
\end{gathered}
$$

Differentiating Eq. (19) by $R_{c}$ and taking the logarithm, one obtains,

$$
\log \left(\partial\left(D_{\mathrm{S}} A / \delta\right)^{2} / \partial R_{c}\right)=\log \alpha-2\left(E_{D}+E_{\eta}^{\prime}\right) / 2.3 R T
$$

The values of $\alpha$ and $E_{D}+E_{\eta}^{\prime}$ can be determined by the intercept and the slope of the straight line obtained by plotting $\log \left(\partial\left(D_{\mathrm{S}} A / \delta\right)^{2} / \partial R_{c}\right)$ against $1 / T$. The values of $\alpha$ and $E_{D}+E^{\prime}{ }_{\eta}$ obtained from Fig. 11 are $1.6 \times 10^{10}$ and $40 \mathrm{kcal} / \mathrm{mol}$ respectively. On the other hand, the value of $\beta$ can be determined from the intercept of the lines, which represent the relationship between $\left(D_{\mathrm{S}} A / \delta\right)^{2}$ and $R_{c}$ in Eq. (21) derived from Eq. (19), as shown in Fig. 10.

$$
\begin{aligned}
\left(D_{\mathrm{S}} A / \delta\right)^{2}= & \alpha R_{c} \exp \left\{-2\left(E_{D}+E_{\eta}^{\prime}\right) / R T\right\} \\
& +\beta \exp \left\{-2\left(E_{D}+E_{\eta}^{\prime}\right) / R T\right\}
\end{aligned}
$$

Table 1 summarizes the values of $\alpha$ and $\beta$, where the values of $\alpha$ except the last column are obtained from the slope of the straight line showing the relationship between $\left(D_{\mathrm{S}} A / \delta\right)^{2}$ and $R_{e}$ in Eq. (21)

The values of $\alpha$ and $\beta$ at three different temperatures agree well excluding the case at $1450^{\circ} \mathrm{C}$, so that this reaction model is confirmed to be valid. The value

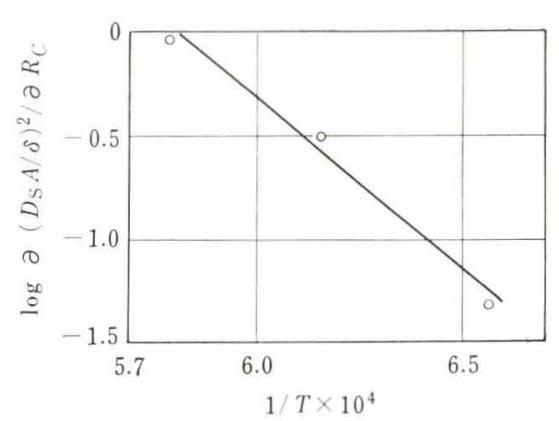

Fig. 11. Relation between $\log \partial\left(D_{\mathrm{S}} A / \delta\right)^{2} / \partial R_{c}$ and $1 / T$ at $1250^{\circ}, 1350^{\circ}$, and $1450^{\circ} \mathrm{C}$

Table 1. Numerical values of $\alpha$ and $\beta$ at $1250^{\circ}, 1350^{\circ}$, and $1450^{\circ} \mathrm{C}$

\begin{tabular}{c|c|c|c|c}
\hline & $1250^{\circ} \mathrm{C}$ & $1350^{\circ} \mathrm{C}$ & $1450^{\circ} \mathrm{C}$ & From Fig. 11 \\
\hline$\alpha$ & $1.4 \times 10^{10}$ & $1.9 \times 10^{10}$ & $1.3 \times 10^{10}$ & $1.6 \times 10^{10}$ \\
\hline$\beta$ & $1.2 \times 10^{10}$ & $1.5 \times 10^{10}$ & $6.7 \times 10^{9}$ & \\
\hline
\end{tabular}

of $\alpha$ in the last column, $1.6 \times 10^{10}$ is considered to be a mean value of those in the temperature range $1250^{\circ}$ to $1450^{\circ} \mathrm{C}$. The mean value of $\beta$ slown in Table 1 is $1.1 \times 10^{10}$. Using the activation energy of viscosity for $\mathrm{Fe}-\mathrm{C}$ alloy, which is calculated from other reference, ${ }^{9)}$ $E_{\eta}{ }^{\prime}$ is obtained to be $4.8 \mathrm{kcal} / \mathrm{mol}$.

If it is the chemical reaction controlled, the activation energy calculated, $40 \mathrm{kcal} / \mathrm{mol}$, would be that of the chemical reaction shown in Eq. (10). Using the values of $7.5 \mathrm{kcal} / \mathrm{mol}^{6}$ ) for $E_{D}$ and $4.8 \mathrm{kcal} / \mathrm{mol}$ for $E_{\eta}{ }^{\prime}$, the difference between the obtained activation energy of $40 \mathrm{kcal} / \mathrm{mol}$ and $E_{D}+E_{\eta}{ }^{\prime}$ is $27.7 \mathrm{kcal} / \mathrm{mol}$. When the other value, $21 \mathrm{kcal} / \mathrm{mol},{ }^{7)}$ is used for $E_{D}$, the difference becomes $14.2 \mathrm{kcal} / \mathrm{mol}$.

If these values, 27.7 and $14.2 \mathrm{kcal} / \mathrm{mol}$, are within the limit of error for $E_{D}+E_{\eta}{ }^{\prime}$, the rate determining step can be considered to be the diffusion of sulphur. However, the value of $35.2 \mathrm{kcal} / \mathrm{mol}$ seems to be too large for the value of the activation energy of diffusion.

On the other hand, the value of the activation energy of chemical reaction may be considered to be $35 \mathrm{kcal} /$ mol which is calculated by dividing the standard enthalpy of $\mathrm{CaC}_{2}, 212 \mathrm{kcal} / \mathrm{mol}$ at $1600^{\circ} \mathrm{K}$ by the number of bonds between $\mathrm{Ca}^{2+}$ and $\mathrm{C}_{2}{ }^{2-}$ which is six. However, it is unable to conclude from this estimation of the activation energy that the process may be the chemical reaction controlled.

Y. Oguti et al.10),11) investigated the desulphurization of carbon saturated liquid iron by the rotating $\mathrm{CaC}_{2}$ cylinder and determined the mass transfer coefficient. According to their results, the activation energy of the mass transfer coefficient is $13.4 \mathrm{kcal} / \mathrm{mol}$. They concluded that the rate determining step was the diffusion of sulphur in the boundary layer of the metal, from the fact that the two above-mentioned were in agreement, when the dimensionless equation proposed by other investigators was used. For the case that $\mathrm{CaC}_{2}$ powder was used as the desulphurizer, the activation energy was reported to be $38 \mathrm{kcal} / \mathrm{mol}$, which agrees with that obtained by present authors. However, the 
observation on the behavior of sintering of $\mathrm{CaC}_{2}$ is opposite to their's, as mentioned above, so that their concept on the relationship between temperature and the interfacial area is not applicable to the results of this study.

The experimental results are expressed by Eq. (22) in terms of mass transport, although the mechanism was not clarified sufficiently.

$$
K=\left(1.6 \times 10^{10} R_{c}+1.1 \times 10^{10}\right)^{1 / 2} \exp (-40000 / R T)
$$

\section{Conclusion}

Although it was not determined whether the rate determining step of desulphurization by the use of a small scale rocking furnace is diffusion or chemical reaction, the mixing of solid $\mathrm{CaC}_{2}$ powder and molten iron was found to be very important for rapid and effective desulphurization.

The effects of temperature and rocking cycle on the desulphurization of carbon saturated iron with $\mathrm{CaC}_{2}$ powder were studied and the experimental results obtained are expressed by the following equation

$$
K=\left(1.6 \times 10^{10} \cdot R_{c}+1.1 \times 10^{10}\right)^{1 / 2} \exp (-40000 / R T)
$$

where, $K$ : the mass transfer coefficient

$R_{c}$ : the rocking speed

$R:$ the gas constant

$$
\text { T: temperature }\left({ }^{\circ} \mathrm{K}\right) \text {. }
$$

\section{Acknowledgements}

The authors wish to express their thanks to Mr. T. Kobayashi, Chita works, Daido Steel Co., Ltd. for his co-operation in carrying out this work.

\section{REFERENCES}

1) B. Kalling, G. Danielsson, and O. Dragge: J. Metals, 3 (1951), 732.

2) T. Ōkuro, G. Mori, N. Hayashi, R. Yanokura, and A. Hukushima: Tetsu-to-Hagané, 50 (1964), 1795.

3) K. Wakabayashi, A. Sotozono, Y. Kuroiwa, and J. Yagi: Tetsu-to-Hagané, 50 (1964), 1797.

4) T. Ōkuro, H. Tomomatsu, W. Iihama, N. Hayashi, R. Yanokura, and J. Jizaimaru: Tetsu-to-Hagané, 52 (1966), 120.

5) G. C. Kuczynski: Sintering and Related Phenomena, (1967), 77, Gordon and Breach Science Publisher, New York.

6) Y. Kawai: J. Japan Inst. Metals, 20 (1956), 514.

7) R. E. Grace and G. Derge: Trans. Met. Soc. AIME, 212 (1958), 331.

8) K. Niwa, H. Ebiko, I. Yamai, and M. Shimoji: Rept. 19th Committee, Japan Soc. Prom. Sci., (1959) No. 5429.

9) J. F. Elliott: Thermochemistry for Steel Making, (1960), 640, Addison Wesley Publishing Co. Inc., London.

10) Y. Oguti, H. Minami, and H. Ooi: Tetsu-to-Hagané, 55 (1969), S158.

11) H. Ooi, Y. Oguti, and H. Minami: Tetsu-to-Hagané, 56 (1970), 991 